\title{
A Study of Change Leadership Roles for School Principals Based on the Perspectives of Competing Values Framework
}

\author{
Tsai-Feng Cheng, Shu-Fen Tseng, and Huei-Chun Wu
}

\begin{abstract}
School ecology is affected by the environment changes. Due to the complexity and variability of these environments, school principals must be able to adjust and change their leadership role. The purposes of this study are listed as follows:

1). to review related theories/researches, and to integrate the context of principals' leadership roles in the organizational change based on competing values framework.

2). to investigate school staffs' different perceptions of principals' change leadership roles.

Besides, there were six hundred and sixty educators filling out the survey questionnaire, adopted from fifty-five vocational schools in Taiwan. Finally, valid data are analyzed with statistical test.

The main conclusions are:

1). Principals show fair performance, and the scores of "control" dimension is higher than "creation" in the importance of role and principals' performance.

2). Lower score is shown in "innovator" dimension and "problem-solver" is emphasized most for the importance.

3). There are some differences in principals' performance and school staffs' expectation for principals' leadership role.
\end{abstract}

Index Terms-Change leadership, competing values framework, leadership roles.

\section{INTRODUCTION}

Due to the impact of a global economic slowdown, declining birthrate, educational environment change, industrial technology transfer and a shift of manufacturing industry in recent years, the demand for non-skilled employees in developing countries has been to decrease [1]. Facing a changing school environment, the principal who is a school leader, should perceive not only an era with changing, competition, and complexity, but also organizational reform, regarded as an evolutionary value process that adapts to the era of change [2].

Many empirical studies indicated principal leadership effectiveness is important in the effective school researches [3]-[6]. There are many reasons for the more likely miserable failures of school reform. However, a non-negligible factor is

Manuscript received March 18, 2019; revised July 14, 2019. This work was supported in part by Ministry of Science and Technology, Taiwan under Grant 97-2410-H-017 -004-MY2.

T. F. Cheng and S. F. Tseng are with the Department of Education, National Kaohsiung Normal University, Kaohsiung, Taiwan (e-mail: t2151@nknu.edu.tw,t1554@nknu.edu.tw).

H. C. Wu is with the Custody Division of Office General Affairs at Kaohsiung Medical University, Kaohsiung, Taiwan (e-mail: yavette@kmu.edu.tw) the lack of effective change leadership. The complexity of the change process makes organizational transformation impossible in a straight line, and adopting effective change leadership strategies to the current school culture is one of the biggest challenges for a leader; therefore, only when a leader can effectively lead the school's change process, school change then can be successful.

There are many paradox phenomenon with the coexistence of contradictory views in an organization [7], [8]. Conflicts and contradictions must exist in the context of both internal integration and external adaptation, as well as the need for stability and resilience. The main function of the competitive value framework (CVF) is to get rid of straight-thinking and single value, showing many Janusian thinking [9]. Seeking a balance for different and even opposite values to effectively deal with the various phenomena in the organization is particularly helpful in interpreting and combining complex organizational phenomena [10].

The CVF, formed by a horizontal axis - internal to external, and a vertical axis - flexibility to stability, is used to develop four quadrants, namely the rational goal model, the open systems model, the human relations model and the internal process model. It applies the concept of competition and opposition in organizational theory, to deal with premise hypothesis, theoretical model and values. Thus, many different thinking and ideas will be presented in the framework [11]. Based on the analysis of the above literature, and statements of [12], this study uses the competitive value framework as the theoretical basis, divided into four areas: rational goal, open systems, human relations, and internal process. In order to understand the leadership role of the technical high school principals in the organizational change, and the related changing conditions and situational characteristics, the CVF is shown in Fig. 1.

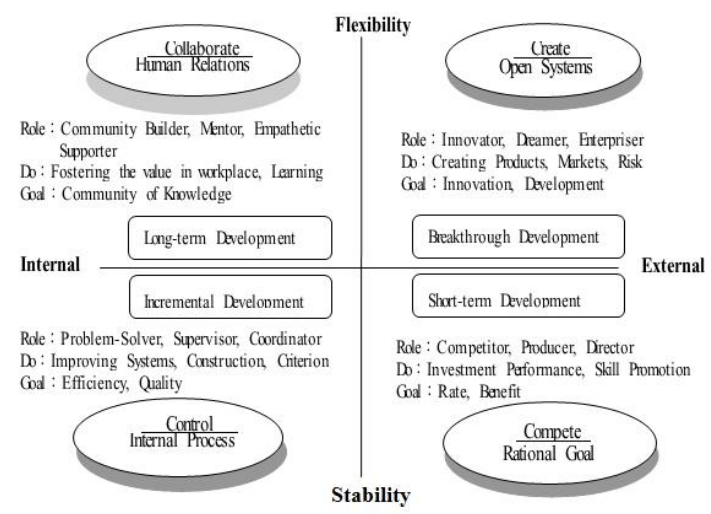

Fig. 1. Competing values framework and organizational change resource compiled and revised by the author. 
In summary, the purpose of this study is: 1) to review related theories/researches, and to integrate the context of principals' leadership roles in the organizational change based on competing values framework. 2) to investigate school staffs' different perceptions of principals' change leadership roles. Based on the research findings, the relevant research and practical suggestions will be submitted.

\section{Methodology}

\section{A. Study Population and Sampling}

In order to verify the validity and reliability of the tools developed in this study, the scale pre-test and the modification of questionnaire was first carried out. In this study, 18 public and private technical high schools were selected. There were 216 samples including principal, full-time teacher, teacher and class tutor, teacher and director, teacher and section chief filling out the pre-test survey. After that, multiple-stage sampling was used to execute the formal survey questionnaire. One-third of the schools were selected from a total of 156 public and private technology high schools in Taiwan, and about 55 schools were used as research samples. 10 to 15 copies of questionnaires were delivered to each sample school according to its school size. Eventually, 660 subjects extracted from those target schools, and there were 625 respondents completing the questionnaires. After deducting eight incomplete copies of questionnaires, a total of 617 valid questionnaires, the rate of valid response data was $93.50 \%$.

\section{B. Research Instruments}

Principal change leadership role scale for the technology high school used in this study, and the pre-test questionnaire mainly consisted 4 dimensions: compete, create, collaborate and control, and 12 subdimensions: producer, competitor, director, dreamer, entrepreneur, innovator, community builder, empathetic supporter, mentor control, problem-solver, supervisor, coordinator, etc.. The original questionnaire in this study had a total of 75 questions; however, in order to avoid respondents from refusing to fill in the questionnaire due to too much time. Only the first 4 questions (i.e., the highest average) were retained in each subdimension except the dimension of collaborate. The scale survey design was the 6-point Likert scales, and the option "1" meant not very important, "6" meant extremely important and the intermediate score was evaluated by "2, 3, 4, 5" according to the degree of importance. Statistical analysis of pre-test results was described as follows.

\section{1) Item analysis}

Comparisons of extreme groups and correlation analysis were employed. The former's critical ratios are all more than 3 , and reach significant standard, showing all items have discriminating power. Values of this pre-test questionnaire for corrected item-total correlations between 0.570 and 0.855 may indicate that the question is discriminating well. When looking at Cronbach's alpha if item deleted, the alpha coefficient of the questionnaire is between 0.913 and 0.955 , which are all within the acceptable range. Overall results show that all the items significantly contributed for acceptable internal consistency of the study.

\section{2) Factor analysis}

Primary axis factoring and the promax method of oblique rotation were adopted to analyze each dimension of the scale of change leadership role. Cumulative variance explained of 4 dimensions:compete, create, collaborate, and control are 64.300, 65.182, 70.810, and 69.722 respectively; moreover, the eigenvalues range from 3.999 to 5.675 . Factor loading of each question in 12 subdimensions is maintained at 0.528 to 0.918; however, there are 5 questions (1 question for community builder; 2 questions for empathetic supporter and mentor) deleted because of low factor loading. A total of 43 questions are finally selected in the formal questionnaire.

\section{3) Reliability analysis}

Cronbach $\alpha$ coefficient of "compete "create", "collaborate" and "control" dimensions are respectively $0.922,0.935,0.943,0.906$; As to the overall dimension of the scale, the Cronbach coefficient is also as high as 0.976. It shows that the reliability of all subdimensions and dimensions of the study can be maintained above 0.90 level, and the internal consistency is very good.

\section{Data Processing}

Data analysis methods used in this study included item analysis, factor analysis, reliability analysis, descriptive statistics, and repeated measure ANOVA.

\section{RESUlTS}

\section{A. Analysis of the Importance of Principals' Change Leadership Role}

\section{1) Overall analysis}

The importance of technology high school principals' change leadership role is shown in Table I. With regard to the importance of overall change leadership role, the average score for each question is 5.39 , which is higher than the average value of each question (Mean = 3.5). And the percentile is $87.8[(M-1) /(N-1), \mathrm{M}$ is the average value of each question, and $\mathrm{N}$ is the number of options], indicating that the principal's change leadership role tends to be highly important. Repeated measure ANOVA is then used to analyze the importance of 4 dimensions and significant difference found among them $(F=21.37, p<0.01)$. After the post hoc comparison testing, the importance of the "control" dimension is significantly higher than that of "compete" and "collaborate" and higher than "create". And hence in face of organizational change, the technology high school principals who play the "control" leadership role will be more important than any other leadership role of compete, collaborate and create.

It can be seen that the current organizational climate in technical high schools is still conservative. So, in order to implement organizational changes with success, relevant institutions and leaders need to encourage all school members to adjust and abandon traditional thinking.

\section{2) Subdimension analysis}

The difference in the importance of each subdimension of technology high school principals' leadership role is shown 
in Table II. The table shows that there are some significant differences among the three leadership roles at the compete dimension: producer>competitor $\&$ director. In the create dimension, there are also some significant differences between the three types of leaders: entrepreneurs and dreamers > innovators. The differences among three types of leadership roles are significant at the collaborate dimension: empathetic supporter $>$ community builder $>$ mentor. And there are significant differences at the control dimension, it is problem solver > coordinator> supervisor. The problem solver is the most important among all leadership roles, and furthermore, the innovator is of the least importance.

TABLE I: MEAN AND STANDARD DEVIATIONS OF THE IMPORTANCE OF PRINCIPALS' CHANGE LADERSHIP ROLES

\begin{tabular}{lcccccc}
\hline $\begin{array}{c}\text { Importance } \\
\text { of } \\
\text { leadership } \\
\text { role }\end{array}$ & $M$ & $S D$ & $\begin{array}{c}\text { Number } \\
\text { of } \\
\text { question }\end{array}$ & $\begin{array}{c}\text { Average } \\
\text { number } \\
\text { of } \\
\text { questions }\end{array}$ & $F$ & $\begin{array}{c}\text { Post hoc } \\
\text { comparison }\end{array}$ \\
\hline $\begin{array}{l}\text { (1)Compete } \\
\text { (2)Create }\end{array}$ & 64.88 & 6.64 & 12 & 5.41 & $21.37^{* *}$ & $(4)>(1)$ \\
$\begin{array}{l}\text { (3)Collaborate } \\
\text { (4)Control }\end{array}$ & 37.70 & 4.42 & 7 & 5.39 & $(3)>(2)$ \\
$\begin{array}{l}\text { Overall } \\
\text { leadership }\end{array}$ & 65.38 & 7.08 & 12 & 5.49 & \\
role & 231.94 & 23.84 & 43 & 5.39 & \\
\hline$* * p<0.01$ & & & & & & \\
\hline
\end{tabular}

TABLE II: MEAN AND STANDARD DEVIATIONS OF SUBDIMENSIONS OF THE IMPORTANCE OF PRINCIPALS' CHANGE LEADERSHIP ROLES

\begin{tabular}{cccccc}
\hline $\begin{array}{c}\text { Importance } \\
\text { of leadership } \\
\text { role }\end{array}$ & $M$ & $S D$ & $\begin{array}{c}\text { Number } \\
\text { of } \\
\text { questions }\end{array}$ & $\begin{array}{c}\text { Average } \\
\text { number } \\
\text { of } \\
\text { questions }\end{array}$ \\
\hline
\end{tabular}

\begin{tabular}{|c|c|c|c|c|c|c|}
\hline \multicolumn{7}{|l|}{ Compete } \\
\hline (1)Producer & 21.96 & 2.26 & 4 & 5.49 & \multirow{3}{*}{$29.46^{* * *}$} & \multirow{3}{*}{$(1)>(2)(3)$} \\
\hline (2)Competitor & 21.45 & 2.58 & 4 & 5.36 & & \\
\hline (3)Director & 21.48 & 2.53 & 4 & 5.37 & & \\
\hline \multicolumn{7}{|l|}{ Create } \\
\hline (1)Dreamer & 21.60 & 2.60 & 4 & 5.40 & \multirow{3}{*}{$58.59^{* * *}$} & \multirow{3}{*}{$(1)(2)>(3)$} \\
\hline (2)Enterpriser & 21.51 & 2.57 & 4 & 5.38 & & \\
\hline (3)Innovator & 20.88 & 2.96 & 4 & 5.22 & & \\
\hline \multicolumn{7}{|l|}{ Collaborate } \\
\hline $\begin{array}{l}\text { (1)Community } \\
\text { builder }\end{array}$ & 16.13 & 2.00 & 3 & 5.38 & \multirow{3}{*}{$19.21^{* * *}$} & \multirow{3}{*}{$(2)>(1)>(3$} \\
\hline $\begin{array}{l}\text { (2)Empathetic } \\
\text { supporter }\end{array}$ & 10.91 & 1.41 & 2 & 5.46 & & \\
\hline (3)Mentor & 10.66 & 1.44 & 2 & 5.33 & & \\
\hline \multicolumn{7}{|l|}{ Control } \\
\hline (1)Problem-solver & 22.09 & 2.39 & 4 & 5.52 & \multirow{3}{*}{$42.00^{* * *}$} & \multirow{3}{*}{$(1)>(3)>(2)$} \\
\hline (2)Supervisor & 21.51 & 2.63 & 4 & 5.38 & & \\
\hline (3)Coordinator & 21.78 & 2.56 & 4 & 5.44 & & \\
\hline
\end{tabular}

The possible reason for the innovators with lowest importance of leadership role is that high school educators reflecting the high school ecology or their expectations for conservative tradition? It is worth further research.

\section{B. Analysis of the Status of Principals' Change Leadership Role}

1) Overall analysis
The actual performance of the technology high school principals' change leadership role is shown by statistical results in Table III. As to the current performance of overall change leadership role, the average score for each question is 4.57 , which is higher than the average value of each question (Mean = 3.5). And the percentile is 71.4 , indicating that the principal's current performance of change leadership tends to be above average. Repeated measure ANOVA is then used to analyze principals' current performance at 4 dimensions of change leadership role and significant difference found among them $(F=9.50, p<0.01)$. After the post hoc comparison testing, principals' performance at the "compete" dimension and "control" dimension is better than that of "create" and "collaborate". In the competitive value framework, "compete" and "control" are both in the lower quadrant. Their common characteristics is "stability and control", while "create" and "collaborate" are in the upper quadrant with the common characteristics of "elasticity and diversity" (see Fig. 1). Therefore, the technology high school principals' change leadership role tends to the characteristics of "stability and control".

TABLE III: MEAN AND STANDARD DEVIATIONS OF THE STATUS OF PRINCIPALS' CHANGE LEADERSHIP ROLES

\begin{tabular}{|c|c|c|c|c|c|c|}
\hline \multicolumn{7}{|c|}{ PRINCIPALS' CHANGE LEADERSHIP ROLES } \\
\hline $\begin{array}{l}\text { Status of } \\
\text { leadership } \\
\text { role }\end{array}$ & $M$ & $S D$ & $\begin{array}{c}\text { Number } \\
\text { of } \\
\text { questions }\end{array}$ & $\begin{array}{l}\text { Average } \\
\text { number } \\
\text { of } \\
\text { questions }\end{array}$ & $F$ & $\begin{array}{l}\text { Post hoc } \\
\text { comparison }\end{array}$ \\
\hline (1) Compete & 55.02 & 11.29 & 12 & 4.58 & $9.50^{* *}$ & $\begin{array}{l}(1)(4)> \\
(2)(3)\end{array}$ \\
\hline (2) Create & 54.38 & 11.73 & 12 & 4.53 & & \\
\hline $\begin{array}{l}(3) \\
\text { Collaborate }\end{array}$ & 31.71 & 7.20 & 7 & 4.53 & & \\
\hline $\begin{array}{l}\text { (4) Control } \\
\text { Overall }\end{array}$ & 55.39 & 11.89 & 12 & 4.62 & & \\
\hline $\begin{array}{l}\text { leadership } \\
\text { role }\end{array}$ & 196.49 & 40.23 & 43 & 4.57 & & \\
\hline
\end{tabular}

\section{2) Subdimension analysis}

The actual performance of technology high school principals in each subdimension of change leadership role is shown in Table IV. The table shows that there are significant differences existed among three leadership roles for each dimension of compete, create, collaborate and control. They are listed below: producer $>$ competitor $>$ director; entrepreneurs $>$ dreamers $>$ innovators; mentor $>$ empathetic supporter $>$ community builder; problem solver $>$ supervisor $>$ coordinator. Among the performance of all leadership roles, problem-solve $r$ is the best and innovator, the role most directly related to organizational change, is the worst. So it can be seen that the technology high school principals should play an innovative leadership role in order to respond, lead and catalyze organizational change.

\section{Comparative Analysis of the Importance and the Status of Principals' Changing Leadership Roles}

The importance and the status principals' changing leadership roles are shown in Table V. It can be found in the table that whether it is the overall change leadership or the four dimensions, the importance of the change leadership role and the current status are significantly different. After 
reviewing the statistical data, the importance is significantly higher than the current status. That is to say, samples in the study generally accept that the actual performance of the principal's change of leadership role is significantly different from the degree of importance they perceive. However, implementing the change leadership roles need to be strengthened for technology high school principals in the future.

TABLE IV: MEAN AND STANDARD DEVIATIONS OF SUBDIMENSIONS OF THE STATUS OF PRINCIPALS' CHANGE LEADERSHIP ROLES

\begin{tabular}{|c|c|c|c|c|c|c|}
\hline $\begin{array}{l}\text { Status of } \\
\text { leadership } \\
\text { role }\end{array}$ & $M$ & $S D$ & $\begin{array}{l}\text { Number } \\
\text { of } \\
\text { questions }\end{array}$ & $\begin{array}{c}\text { Average } \\
\text { number } \\
\text { of } \\
\text { questions }\end{array}$ & $F$ & $\begin{array}{l}\text { Post hoc } \\
\text { comparison }\end{array}$ \\
\hline \multicolumn{7}{|l|}{ Compete } \\
\hline (1)Producer & 18.60 & 3.83 & 4 & 4.65 & \multirow{3}{*}{$29.49^{* * *}$} & \multirow{3}{*}{$(1)>(2)>(3)$} \\
\hline (2)Competitor & 18.37 & 3.94 & 4 & 4.59 & & \\
\hline (3)Director & 18.04 & 4.05 & 4 & 4.51 & & \\
\hline \multicolumn{7}{|l|}{ Create } \\
\hline (1)Dreamer & 18.17 & 4.13 & 4 & 4.54 & \multirow{3}{*}{$42.03 * * *$} & \multirow{3}{*}{$(2)>(1)>(3)$} \\
\hline (2)Enterpriser & 18.50 & 4.03 & 4 & 4.62 & & \\
\hline (3)Innovator & 17.71 & 4.14 & 4 & 4.43 & & \\
\hline \multicolumn{7}{|l|}{ Collaborate } \\
\hline $\begin{array}{l}\text { (1)Community } \\
\text { builder }\end{array}$ & 13.43 & 3.32 & 3 & 4.71 & \multirow{3}{*}{$38.43 * * *$} & \multirow{3}{*}{$(3)>(2)>(1)$} \\
\hline $\begin{array}{l}\text { (2)Empathetic } \\
\text { supporter }\end{array}$ & 9.25 & 2.30 & 2 & 4.63 & & \\
\hline (3)Mentor & 10.85 & 1.44 & 2 & 5.43 & & \\
\hline \multicolumn{7}{|l|}{ Control } \\
\hline (1)Problem-solver & 18.83 & 4.00 & 4 & 5.52 & \multirow{3}{*}{$40.25^{* * *}$} & \multirow{3}{*}{$(1)>(2)>(3)$} \\
\hline (2)Supervisor & 18.50 & 4.05 & 4 & 5.38 & & \\
\hline (3)Coordinator & 18.06 & 4.38 & 4 & 4.52 & & \\
\hline
\end{tabular}

As to the 4 dimensions of competing value framework, the dimension which has most direct relationship with change is "create" (open systems). However, from the perspective of the principal's change of leadership role, the change leadership role with creation orientation is rated as the least important, and the actual performance is also the weakest. The deeper meaning and the phenomena reflected in the school operation need to be further investigated.

TABLE V: MEAN, STANDARD DEVIATIONS AND T-VALUE OF THE IMPORTANCE AND STATUS OF PRINCIPALS' CHANGE LEADERSHIP ROLES

\begin{tabular}{llccc}
\hline \multicolumn{2}{c}{ Variable } & $M$ & $S D$ & t-value \\
\hline Compete & Importance & 5.41 & 0.55 & 22.72*** \\
(Rational goal) & Status & 4.58 & 0.94 & \\
Create & Importance & 5.33 & 0.63 & $20.77 * * *$ \\
(Open systems) & Status & 4.53 & 0.98 & \\
Collaborate & Importance & 5.39 & 0.63 & $20.57 * * *$ \\
(Human relations) & Status & 4.53 & 1.03 & \\
Control & Importance & 5.45 & 0.59 & $21.28 * * *$ \\
(Internal process) & Status & 4.62 & 0.99 & \\
Overall leadership & Importance & 5.39 & 0.55 & $22.83 * * *$ \\
role & Status & 4.57 & 0.94 & \\
\hline$* * * p<0.001$ & & & &
\end{tabular}

$* * * p<0.001$
As to the 4 dimensions of competing value framework, the dimension which has most direct relationship with change is "create" (open systems). However, from the perspective of the principal's change of leadership role, the change leadership role with creation orientation is rated as the least important, and the actual performance is also the weakest. The deeper meaning and the phenomena reflected in the school operation need to be further investigated.

\section{CONCLUSION AND SUGGESTION}

\section{A. Conclusion}

1) Principals' change leadership role is highly important, but principals only present moderate performance. Regardless of importance or actual performance, the "control" dimension is higher than "create".

The indicator of principals' change leadership role is highly important. The importance of "control" dimension is higher than "compete", "collaborate", and "create". But principals only present moderate performance currently. Their actual performance of leadership role at the dimensions of "compete" and "control" are higher than "create" and "collaborate"; in short, the "create" dimension is sorted at the end.

2) On the importance and current performance of principals' change leadership role, the score of the innovator is the lowest, and most emphasize the importance of the role for the problem solver.

As to the importance and actual performance at each dimension and subdimension of principals' change leadership role, the score of innovator is the lowest, but the role of the problem solver is considered more important. In fact, the innovator is one of the important core roles in change organization, so that is why the teaching staffs and the principal of technology high school all should emphasize the importance of innovation and show more innovative performance in order to promote and respond to changes in technology high schools. It is also commendable that the technology high school principal has been highly recognized as a good mentor role by the school staff in providing teachers with support and care.

3) School staffs have a gap between the expectations and actuality on the perception of principals' change leadership role.

School staffs think that the expectations on the importance of principals' change leadership role is apparently higher than their actual performance; that is, principals should have worked hard to improve their performance in leadership roles.

\section{B. Suggestion}

1) Technology high school principals' change leadership roles should be interpreted from the perspective of compatible thinking.

In the organizational theory, the development of the organization based on "change" that tend to the value of "create" in open systems mode. However, from this study, it is found that the role of change leadership is not only to emphasize "create", but also to "compete", "collaborate", and 
"control". That is also to say that the technology high school principals must be able to effectively demonstrate the role of change leadership based on compatible thinking in competing values framework. In addition, "create" can be used as the basis and take advantage of the different leadership roles to achieve the desired goals of change leadership.

2) The technology high school principals can select the required indicators of change leadership role according to the different objectives.

There are 12 change leadership roles with competing values provided in this study. If school principals are unable to fully apply these indicators, it is suggested that according to school characteristics, and stage of development, they may select a number of effective role indicators in order to meet the flexibility of school management.

3) Strengthening the school principals' performance of the "create" leadership role, particularly the strengthening of the role of innovators.

It can be found in the study that principals can obtain the high score of "control" performance during the organizational change, but relatively the lowest score in "create", especially the role of the innovator is listed at the end, both in terms of importance or actual performance. This phenomenon can meet the expectations from school staffs, but in order to improve school principals to effectively face the all-round organizational phenomenon in the organizational change, school principals should not only focus on internal and control but also play with "create" leadership role emphasizing external and flexibility. Moreover, strengthening innovation, adaptation, development, external support and access to resources, emphasizing flexible leadership are also important for school leaders.

\section{CONFLICT OF INTEREST}

The authors declare no conflict of interest.

\section{AUTHOR CONTRIBUTIONS}

T. F. Cheng created the research paper topic and framework, and finalized the research paper; S. F. Tseng assisted in delivering the questionnaire and data coding; H. C. $\mathrm{Wu}$ organized the research literature, analyzed the data, and wrote the draft of research paper; all authors had approved the final version.

\section{REFERENCES}

[1] I. S. Gill, F. Fluitman, and A. Dar, Vocational Education and Training Reform: Matching Skills to Markets and Budgets, New York, N.Y.: Oxford University Press, 2000.

[2] C. W. Liao, "The stud y of the influence of organizational change trends on educational administration theory, construction, and practice," JNTTC, vol. 15, pp. 1-60, 2001.
[3] L. Alammar, "The effective school: The role of the leaders in school effectiveness," Educational Research and Reviews, vol. 10, no. 6, pp. 695-721, 2015.

[4] K. Leithwood and D. Jantzi, "Linking leadership to student learning: The contributions of leader efficacy," Educational Administration Quarterly, vol. 44, pp. 496-528, 2008.

[5] M. T. Orr and S. Orphanos, "How graduate-level preparation influences the effectiveness of school leaders: A comparison of the outcomes of exemplary and conventional leadership preparation programs for principals," Educational Administration Quarterly, vol. 47, no. 1, pp. 18-70, 2011.

[6] V. M. J. Robinson, C. A. Lloyd, and K. J. Rowe, "The impact of leadership on student outcomes: An analysis of the differential effects of leadership types," Educational Administration Quarterly, vol. 44, pp. 635-674, 2008.

[7] D. R. Denison, R. Hooijberg, and R. E. Quinn, "Paradox and performance: Toward a theory of behavioral complexity in managerial leadership," Organizational Science, vol. 6, no. 5, pp. 524-540, 1995.

[8] R. E. Quinn and M. R. McGrath, "The transformation of organizational cultures: A competing values perspective," Organizational Culture, Beverly Hills, CA: Sage, 1985, pp. 315-334.

[9] R. M. O'Neill and R. E. Quinn, "Editors' note: Applications of the competing values framework," Human Resource Management, vol. 32, no. 1 , pp. $1-7,1993$

[10] K. S. Cameron and R. E. Quinn, Diagnosing and Changing Organizational Culture, Reading, MA: Addison-Wesley, 1999.

[11] T. F. Cheng and H. C. Wu, "A study of the relationships among evaluations of elementary school principals' competing values leadership effectiveness, attitudes towards 360 degree feedback and their behavior change intention," Education Policy Forum, vol. 12, no. 2, pp. 177-217, 2009.

[12] K. S. Cameron, R. E. Quinn, J. Degraff, and A. V. Thakor, Competing Values Leadership: Creating Value in Organizations, Massachusetts: Edward Elgar Press, 2006.

Copyright $(\mathcal{C} 2019$ by the authors. This is an open access article distributed under the Creative Commons Attribution License which permits unrestricted use, distribution, and reproduction in any medium, provided the original work is properly cited (CC BY 4.0).

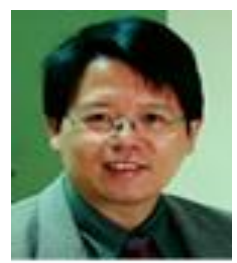

Tsai-Feng Cheng is a professor in the Department of Education, National Kaohsiung Normal University, Taiwan. His specialties include educational administration, educational evaluation, educational leadership and organizational behavior.

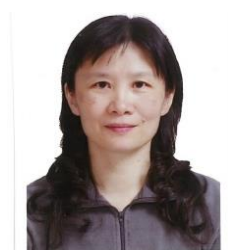

Shu-Fen Tseng is a research assistant in the Department of Education, National Kaohsiung Normal University, Taiwan. She also assists professor Cheng with evaluation affairs.

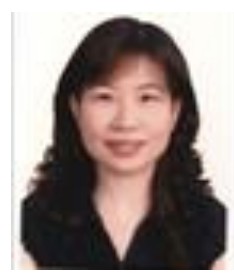

Huei-Chun $\mathbf{W u}$ is currently a director of Custody Division of Office General Affairs at Kaohsiung Medical University, Taiwan. She received her Ph.D. degree in the Department of Adult Education from National Kaohsiung Normal University, Taiwan. Her interests in research include educational administration and management, higher education, educational evaluation, and organizational behavior. She is also an adjunct assistant professor of Kaohsiung Medical University. 